\title{
A systematic critical review of epidemiological studies on public health concerns of municipal solid waste handling
}

\author{
France Ncube, \\ University of Pretoria, Private Bag 323, Pretoria 0007,South Africa \\ Email: france.ncube257@gmail.com \\ Esper Jacobeth Ncube, \\ University of Pretoria,Pretoria, South Africa \\ Kuku Voyi \\ University of Pretoria,Pretoria, South Africa
}

\begin{abstract}
Aims:

The ultimate aim of this review was to summarise the epidemiological evidence on the association between municipal solid waste management operations and health risks to populations residing near landfills and incinerators, waste workers and recyclers. To accomplish this, the sub-aims of this review article were to (1) examine the health risks posed by municipal solid waste management activities, (2) determine the strengths and gaps of available literature on health risks from municipal waste management operations and (3) suggest possible research needs for future studies.
\end{abstract}

\section{Methods:}

The article reviewed epidemiological literature on public health concerns of municipal solid waste handling published in the period 1995-2014. The PubMed and MEDLINE computerised literature searches were employed to identify the relevant papers using the keywords solid waste, waste management, health risks, recycling, landfills and incinerators. Additionally, all references of potential papers were examined to determine more articles that met the inclusion criteria.

\section{Results:}

A total of 379 papers were identified, but after intensive screening only 72 met the inclusion criteria and were reviewed. Of these studies, 33 were on adverse health effects in communities living near waste dumpsites or incinerators, 24 on municipal solid waste workers and 15 on informal waste recyclers. Reviewed studies were unable to demonstrate a causal or non-causal relationship due to various limitations.

\section{Conclusion:}

In light of the above findings, our review concludes that overall epidemiological evidence in reviewed articles is inadequate mainly due to methodological limitations and future research needs to develop tools capable of demonstrating causal or non-causal relationships between specific waste management operations and adverse health endpoints.

Keywords: municipal solid waste, epidemiological studies, risk 


\section{Introduction}

Several epidemiological studies conducted in both developed and developing countries have suggested that municipal solid waste management is a risky and life-threatening activity for populations residing near landfills and waste incinerators, for municipal waste workers and for informal waste recyclers.

A central theme in literature reviewed in this article is that the major health problems of populations residing near landfills and incinerators are cancer, low birth weight, congenital anomalies and Down's syndrome and for municipal waste workers and recyclers the health problems are musculoskeletal disorders, injuries, respiratory, gastro-intestinal and skin conditions. Unfortunately, these epidemiological studies have essentially neglected several critical aspects on the human health risks of municipal solid waste handling.

Noteworthy, all the studies reviewed in this article on cancer risks on populations residing near landfill sites or former sites merely suggest either elevated or no risk, but none has conclusively identified a causal or non-causal relationship between cancers and landfills for such populations.

Equally important, a major limitation of some studies on cancer, low birth weight and congenital anomalies in populations near municipal landfills is their failure to account for potential sources of error like misclassification of waste sites, operating dates of landfills and non-examination of possible effects of multiple or differential exposures from different sites. ${ }^{1-3}$ However, on the positive, it is noteworthy that, despite these shortcomings, some of these studies were very large and had high power. ${ }^{1,2,4}$

Some studies of residents potentially exposed to landfills reported an elevated risk of cancers of the pancreas and liver ${ }^{2}$, kidneys ${ }^{2,5}$ and bladder. ${ }^{5}$ Additionally, Gensburg et al. ${ }^{5}$ reported higher bladder cancers in exposed children. With regard to the popular Love Canal landfill, Gensburg et al. ${ }^{5}$ concur that the role of exposure to the landfill is unclear, given limitations such as a relatively small and incomplete study cohort, imprecise measurements and the exclusion of cancers diagnosed before 1979.

Noteworthy, most studies on municipal waste workers have regrettably negated performing exposure assessments for waste handlers. Epidemiological studies with exposure classification based on field measurement are needed, both to further identify high-risk work conditions and to provide a detailed basis for establishment of occupational exposure limits for mechanical and energetic load particularly in relation to pulling and tilting of containers. ${ }^{6}$ Evidently, non-conduction of exposure assessments in this body of research does not allow for strong evidence-based conclusions to be drawn regarding exposure levels and associated health effects of municipal solid waste handling. There is need for an appropriate risk assessment that informs local government structures and relevant sectors on the health risks associated with different waste management technologies.

Finally, while most studies on waste handling have revealed abundant evidence on respiratory complaints among waste handlers, a lot of research needs to be done on other associated health problems of waste handling. While moderate evidence is available to support that waste collection increases the risk of respiratory complaints, there is limited evidence on gastro-intestinal complaints and hearing loss. ${ }^{7}$ This suggests that research on occupational health risks of waste handlers has not been exhaustive but is rather limited in its coverage of occupational health risks of municipal solid waste handling. There is therefore a paucity of information on other occupational health problems of waste handling. 


\section{Review}

\section{Method}

The PubMed and MEDLINE computerised literature searches were employed to identify the relevant papers using the keywords solid waste, waste management, health risks, recycling, landfills and incinerators. We also examined the references of all potential papers and found more articles that met the inclusion criteria. A total of 379 papers were identified, but after intensive screening only 72 met the inclusion criteria. Of these studies, 33 were on adverse health effects in communities living near dumpsites or incinerators, 24 on municipal solid waste workers and 15 on informal waste recyclers. The inclusion criteria required that the papers reviewed (1) be journal articles published in the period 1995-2014; (2) focus on municipal solid waste management risks to nearby populations, municipal waste workers and informal recyclers; and (3) be articles written in English language. Articles on sewage were excluded from the review since sewage is not part of municipal solid waste. Also articles published prior to 1995 were considered less recent and consequently excluded from this review. Notably, various parameters were employed to assess the epidemiological evidence of human health risks from municipal solid waste management. First, on cancer studies we weighed epidemiological evidence in reviewed cancer studies guided by the criteria set by the International Agency for Research on Cancer (IARC) of 1999, pages 14-25. Notably, the criteria allow for ranking of epidemiological evidence provided by cancer studies in terms of being sufficient, inadequate and limited. Good quality studies revealing a causal or non-causal relationship between exposures and adverse health endpoints were classified as 'sufficient', while 'inadequate' studies were of poor quality to reliably support the presence or absence of a causal association. On the other hand, 'limited' scientific evidence denotes a scenario where a positive causal relationship between exposure and adverse health outcomes has been noted but no provision exists to significantly rule out confounding factors and chance. Second, for studies on other health endpoints other than cancer, we assessed their quality by examining the strengths and limitations in the study methods used. In particular, we noted whether the study used a study type capable of proving causality, a large sample size, a large reference group and controlled for possible confounders, and whether it was a single-centre or multicentre study. Data extraction tables are also provided so that readers can assess the systematic review process used.

\section{Results and Discussions}

\section{Cancer}

Cancer risks associated with residence near landfill sites have been extensively researched and entail cancers of the stomach, liver, intrahepatic bile ducts, cervix, skin and pancreas. While high incidence of cancers for populations residing near landfills has been reported, ${ }^{2,3,5,8-13}$ Jarup et al. ${ }^{1}$ did not find any excess cancer risks for such populations. Clearly, there appears to be no complete congruence among researchers on the cancer risk to communities living near landfill sites or waste incinerators. The majority of ecological study designs used had no capacity to prove causal or non-causal relationships between residence near landfills or incinerators and investigated adverse health effects. This can mainly be attributed to non-performance of individual-level exposure assessments and failure to control for confounding variables.

In Great Britain, Jarup et al. ${ }^{1}$ conducted an ecological study in which they defined the exposed population group as people living within $2 \mathrm{~km}$ of 9,565 landfill sites that were operational at some time from 1982 to 1997 and the reference group as populations living more than $2 \mathrm{~km}$ from a landfill. Notably, Jarup et al. ${ }^{1}$ did not find any excess risks for bladder cancer, brain cancer, hepatobiliary cancer, adult leukaemia and child leukaemia even after adjusting for age, sex, region, year and deprivation. A remarkable strength of Jarup et al.' ${ }^{1}$ study is that it was large and had high power. In light of the following limitations which grossly impinge on the capacity of Jarup et al. ${ }^{1}$ to conclusively demonstrate causality, our review considers evidence of non-causal relationship in Jarup 
et al. ${ }^{1}$ 'inadequate'. First, with regard to their own study, Jarup et al. ${ }^{1}$ concur that potential sources of error like misclassification of waste sites, operating dates of landfills, non-examination of possible effects of multiple or differential exposures from different sites could have dwarfed their study's ability to detect any adverse health effects. Additionally, misclassification of exposure could not be ruled out since the study did not account for potential bias in scenarios where pregnant mothers migrated away from their usual residence in the concerned study period. Moreover, the study was not immune to ecological fallacy since group level rather than individual exposure level assessments were done. Also, Jarup et al. ${ }^{1}$ used a rather small reference group in relation to the exposed group.

Goldberg et $_{\text {al. }}{ }^{2}$ conducted a case-control study on municipal solid waste landfills using geographic zone and distance from the landfill site as exposure estimates and found excess risk of cancer of the pancreas (2.2), prostrate (1.5) and non-Hodgkin lymphomas (2.0). Arguably, while the study by Goldberg et al. ${ }^{2}$ was remarkably very large and had high power, unfortunately the weight of this study's findings can also be classified as inadequate since a very small control group which was over seven times less than the study subjects' was used and this may have impaired the study's results.

Also, case-control designs have difficulties in proving causality due to their retrospective direction of enquiry, inability to stringently manipulate and control study variables and their excessive reliance on available secondary data that may be often incomplete and gathered for a different purpose. However, Goldberg et al. ${ }^{2}$ need to be credited for their use of unconditional regression models to estimate odds ratios.

In Helsinki, Pukkala and Pönkä ${ }^{3}$ found the relative cancer risk for inhabitants of houses built in a former dumpsite to increase slightly with the number of years lived in the area. Noteworthy, evidence of cancer risk on inhabitants of houses built in a former dumpsite in Pukkala and Pönkä's ${ }^{3}$ study seems inadequate for the following reasons. The study only adjusted for demographic characteristics like age and sex and noted an excess of skin and pancreatic cancers but unfortunately negated adjustment for vital confounding variables like lifestyle risk factors such as smoking and alcoholism. Arguably, this is a major loophole of this study since for pancreatic cancer the World Health Organization classifies smoking as a sufficient human carcinogen and alcoholism as a carcinogen with limited evidence. Additionally, like many other ecological designs, the study succumbs to ecological fallacy since it did not measure or model individual-level exposures but rather performed group-level environmental measurements for landfill soil and air pollutants. Nevertheless, the study had a large sample size with a bigger reference group.

Gensburg et al. ${ }^{5}$ observed elevations of bladder cancers for children and elevations of both bladder and kidney cancers for residents exposed to the Love Canal landfill. However, in explaining these excess risks in Gensburg's study, the role of exposure to the landfill is unclear, given limitations such as a relatively small and incomplete study cohort, imprecise measurements and the exclusion of cancers diagnosed before $1979 .{ }^{5}$ Consequently, epidemiological evidence in this study is inadequate to support causality.

Comba et ${ }^{8}{ }^{8}$ investigated the association between occurrence of soft tissue sarcomas (STS) in Mantua and residence near an incinerator of industrial wastes using 37 STS cases and 171 controls matched for sex and age and reported a significant increase in risk of STS associated with residence within $2 \mathrm{~km}$ of an industrial waste incinerator. Notably, the strength of this study was the attempt to have about five randomly selected controls for each case. However, the evidence of causality is limited in this study. The category for limited is justified on the basis that matching controls and cases was done, but case-control designs cannot demonstrate causality as already discussed earlier.

Nevertheless, a small sample size was used and the study did not account for potential confounders like socio-economic factors and other sources of exposures like landfills. According to Portia et al. ${ }^{14}$ a major limitation of Comba et al.' $\mathrm{s}^{8}$ study is the possibility that increased attention to the diagnosis of STS in the vicinity of the Mantua incinerator plant could have introduced bias in the risk estimate. 
In Italy, Zambon et al. ${ }^{9}$ conducted a population-based case-control study on the risk of sarcoma from incinerator and industrial plants on dioxin emissions and found a statistically significant increase in sarcoma risk to both the level and the length of environmentally modelled exposure to dioxin-like substances and their results were more significant for women than for men. Zambon et al. ${ }^{9}$ tried to minimise the effect of confounding factors by matching three controls for age and sex with each of the 205 sarcoma cases, thus producing a comparable reference group. Consequently, epidemiological evidence on sarcoma risk from incinerators is limited. Notably, a small sample size was used and historical data used could have been incomplete for their study purposes and the study did not measure the effect of potential confounders like socio-economic factors and occupational exposures.

In Italy, Biggeri and Catelan ${ }^{11}$ investigated the relationship between various sources of pollution and lung cancer using a case-control study and reported higher relative risk towards the source and radical decrease away from it. Epidemiological evidence linking incinerators with lung cancer is limited in this study. First, residual confounders from unmeasured confounders cannot be excluded, ${ }^{11}$ and a small sample size is used. Additionally, very little information can be obtained from the study regarding the types of chemical pollutants and levels from the incinerators studied. In addition, the purely distance-based surrogate of exposure assessment used further limits the demonstration of causality issues.

In Great Britain, an ecological study by Elliott et al. ${ }^{10}$ investigating cancer incidence in over 14 million people living near 72 municipal solid waste incinerators between 1974 and 1987 found statistically significant $(\mathrm{p}<0.05)$ decline in risk with distance for all cancers, stomach, colorectal, liver and lung cancers. This study was large and had more power, thus its epidemiological evidence can be classified as limited. Regrettably, their study findings need to be considered with caution since even the authors admitted that residual confounding bias and misdiagnosis might have increased their risk estimates. Additionally, an ecological study design can only provide association but cannot prove causality. Thus, it is difficult to classify Elliott et al.' ${ }^{10}$ study findings under the sufficient category. However, a further study by Elliott et al. ${ }^{15}$ on histopathological and case note review of primary liver cancers reported as low as $0.53-0.78$ excess cases compared to the prior 0.95 cases per $10^{5}$ per year within $1 \mathrm{~km}$ from the landfill. Noteworthy, the findings from the improved study of Elliott et al. ${ }^{15}$ need to be treated with caution due to non-availability of histopathological material or case notes for half of the 235 cases in their study.

\section{Birth weight}

Increased incidence of low birth weight in populations living near landfill sites has been observed. ${ }^{4,16-}$ ${ }^{18}$ Noteworthy, none of these studies ${ }^{16-18}$ examined the contribution of exposures at individual level for the pregnant mothers studied particularly in terms of exposure doses and duration. Additionally, these studies did not control for possible vital confounders like occupational exposures and migration out of the 1- to 2-km residence from the landfill for the pregnant mothers in the study period. The purely distance-based surrogate of exposure assessment is not enough to support causality issues. Nevertheless, some studies were large and had more power. ${ }^{4}$ Based on these loopholes, it is not possible to conclude with certainty that maternal residence near landfills during pregnancy has teratogenic effects culminating in increased risk of giving birth to a baby with a low or very low birth weight.

\section{Congenital malformations}

Congenital anomalies in relation to residence near landfill sites are discussed in this article. Two of these studies reported increased risk of congenital anomalies ${ }^{19,20}$ and the remainder found little or no excess risk for such populations. ${ }^{15,21-23}$ On the positive, all of these studies ${ }^{15,19-23}$ were multi-centre studies and some used a larger reference group. ${ }^{19,20}$ Notably, results from multi-centre studies unlike those from single-centre studies have wider application. Regrettably, none of the studies ${ }^{15,19-23}$ had mechanisms to address biases arising from possible exposure misclassification. Additionally, a few 
studies adjusted for age as a potential confounder ${ }^{19,20}$ but regrettably negated measuring effect of potential confounders like socio-economic factors. Also, none of these studies pushes back our boundaries of ignorance with regard to the types and quantities of toxic chemicals in the various hazardous landfills studied. Conclusively, this review argues that very little capacity, if any, is available in these studies with regard to demonstrating causal or non-causal relationships between residence closer to hazardous landfills or incinerators and adverse health effects on such populations.

\section{Respiratory and other diseases}

In Finland, Pukkala and Pönkä ${ }^{3}$ evaluated the prevalence of cancer and asthma in relation to residence in houses built on a former dumping area containing industrial and household wastes. Their study revealed that prevalence of asthma was significantly higher in the dump cohort than those living nearby but outside the landfill site. While this study provides some crucial insights, its worthiness is questionable given the fact that it unfortunately has not been replicated and the overall evidence may be inadequate. ${ }^{14}$ Additionally, in Swaziland, Abul ${ }^{24}$ found that residents with houses built less than $200 \mathrm{~m}$ from the dumpsite were victims of malaria, chest pains, cholera and diarrhoea. However, findings from this study need to be treated with caution since a small sample size of 39 exposed participants and 39 participants in the reference group was used. Furthermore, health effects of dumpsites on residents in Abul's ${ }^{24}$ study are only based on self-reported complaints of research participants which could have introduced recall bias and inflated risk estimates.

\section{Heavy metals in waste disposal sites}

Several studies conducted in developing countries have reported high levels of heavy metals in municipal waste disposal sites. ${ }^{25-28}$ Most waste disposal sites in developing countries are poorly sited, ${ }^{29,30}$ constructed and managed ${ }^{31-33}$ despite handling hazardous waste from industries and medical facilities. Arguably, at the heart of the problems of solid waste management are the absence of adequate policies, enabling legislation and an environmentally stimulated and enlightened public. ${ }^{33-35}$ However, none of these studies went a step further to demonstrate causality between the heavy metals found and human health risks for populations residing near such sites (see online supplementary material, Table 1).

\section{Studies on municipal waste workers}

Municipal solid waste management has been associated with various adverse health problems for waste workers which entail respiratory problems, ${ }^{36-43}$ musculoskeletal disorders, ${ }^{36,44-51}$ injuries, ${ }^{36,52-55}$ nail infection ${ }^{42}$ and inflammation of biomarkers. ${ }^{56}$ Noteworthy, most of the studies employed a descriptive cross-sectional design and were single-centre studies. This suggests that they had no capacity to definitively demonstrate a causal or non-causal relationship between municipal solid waste handling and adverse occupational health endpoints. Additionally, most studies used a small sample size, ${ }^{38-41,43,44,49-51,54-56}$ thus dwarfing the applicability of their findings to a wider population of waste workers. Furthermore, several of these studies negated enrolling a comparison group. ${ }^{50,51,54,55,57}$ Notably, most of the few studies that enrolled a reference group tended to use a smaller group than the waste workers cohort. ${ }^{36,37,44,56,57}$ Some studies did not control for possible confounders like selection bias and smoking. ${ }^{38-41,56}$ One study was longitudinal ${ }^{43}$ but regrettably used a small sample size with a very small reference group, thus dwarfing its value to the wider scientific community. Another study consisting of a larger sample size and reference was conducted in Denmark, ${ }^{58}$ but unfortunately it was cross-sectional and had limitations with regard to proving causality. Overall, these various limitations of epidemiological studies for waste workers suggest that their findings need to be interpreted with caution and that more carefully designed studies are needed to yield more reliable insights on health risks of waste workers. 
A central theme in these studies is the fact that waste recyclers are prone to health problems like injuries,${ }^{59-62}$ respiratory problems,${ }^{60,63-65}$ diarrhoea,${ }^{64,66}$ infections,${ }^{64}$ psychological disorders,${ }^{62}$ chemical hazards ${ }^{61,67-69}$ and musculoskeletal complaints. ${ }^{62,64,67-70}$ Most studies on waste recyclers had more or less similar limitations discussed on studies on waste workers. Notably, most studies used the cross-sectional design, thus dwarfing their capacity to prove causality issues. Equally important, several of these studies ${ }^{31,60-65,67-69,71}$ did not enrol a reference group. Consequently, it is unclear whether it is safe to associate their reported adverse health effects strongly with municipal solid waste management exposures. Still some studies purely relied only on qualitative data in the form of verbal reports from research participants ${ }^{59,72}$ which may have introduced recall bias in their results. Probably, triangulating respondents' verbal reports using additional techniques like lung function tests and environmental exposure assessments could have added value to such studies (see online supplementary material, Table 2).

\section{Conclusion}

In the final analysis, studies reviewed in this article have suggested that municipal solid waste management presents adverse health endpoints not just to formal municipal waste workers but also to informal recyclers and populations residing near waste landfills and incinerators. Noteworthy, a major limitation of the studies reviewed in this article is their failure to provide a causal relationship between waste management processes and adverse health effects. Based on the major findings from this review, it is recommended that future studies focus on the development of tools capable of providing causal relationships between adverse health endpoints and specific waste management operations.

\section{Acknowledgements}

The authors hereby declare that the study was wholly self-funded and no grant whatsoever was received. The emotional support rendered by colleagues is greatly treasured. F.N. conducted the literature searches and developed the manuscript. E.J.N. conceived the review title, guided the development of the article, critically revised it adding vital intellectual input and gave final approval for its submission for publishing. K.V. provided intellectual thought in the drafting, coordination and revision of the manuscript. All authors read and approved the final article.

Conflict of Interest The author(s) declared no potential conflicts of interest with respect to the research, authorship and/or publication of this article.

Ethical Issues The article only critically summarises published articles and does not have any images, videos or voice recordings of participants. The study does not contain any trials of health-care interventions or pilot or preliminary studies of trials.

\section{References}

1. Jarup L, Briggs S, de Hoogh C, . Cancer risks in populations living near landfill sites in Great Britain. British Journal of Cancer 2002; 86: 1732-6.

Goldberg MS, Siemiatyck J, De War R, . Risks of developing cancer relative to living near a

2. municipal solid waste landfill site in Montreal, Quebec, Canada. Archives of Environmental Health 1999; 54: 291-6.

3. Pukkala E, Pönkä A. Increased incidence of cancer and asthma in houses built on a former dump area. Environmental Health Perspectives 2001; 109: 1121-5.

4. Elliott P, Briggs D, Morris S, . Risk of adverse birth outcomes in populations near landfill sites. 
British Medical Journal 2001; 323: 363-8.

5. Gensburg L, Pantea C, Fitzgerald EJ, . Cancer incidence among former Love Canal residents. Environmental Health Perspectives 2009; 117: 209-16.

6. Poulsen O, Breum N, Ebbehoj N. Collection of domestic waste: Review of occupational health problems and their possible causes. Science of the Total Environment 1995; 170: 1-19.

7. Kuijer PP, Sluiter JK, Frings-Dresen MH. Health and safety in waste collection: Towards evidencebased worker health surveillance. American Journal of Industrial Medicine 2010; 53: 1040-64.

8. Comba P, Ascoli V, Belli S, . Risk of soft tissue sarcomas and residence in the neighbourhood of an incinerator of industrial wastes. Occupational \& Environmental Medicine 2003; 60: 650-83.

Zambon P, Ricci P, Bovo E, . Sarcoma risk and dioxin emissions from incinerators and industrial

9. plants: A population-based case-control study. Occupational \& Environmental Medicine 2007; 6: 19.

10. Elliott P, Shaddick G, Kleinschmidt I, . Cancer incidence near municipal solid waste incinerators in Great Britain. British Journal of Cancer 1996; 73: 702-10.

Biggeri A, Catelan D. Mortality for non-Hodgkin lymphoma and soft-tissue sarcoma in the

${ }^{11 .}$ surrounding area of an urban waste incinerator. Campi Bisenzio (Tuscany, Italy) 1981-2001. Epidemiologia e prevenzione 2005; 29: 156-9 (in Italian).

12. Floret N, Mauny F, Challier B, . Dioxin emissions from a solid waste incinerator and risk of nonHodgkin lymphoma. Epidemiology 2003; 14: 392-8.

Fielder HM, Poon-King CM, Palmer SR, . Assessment of the impact on health of residents living

13. near the Nant-y-Gwyddon landfill site: Retrospective analysis. British Medical Journal 2000; 320: $19-22$.

14. Portia D, Milani S, Lazarrino AI, . Systematic review of epidemiological studies on health effects associated with management of solid waste. Environmental Health 2009; 8: 60.

Elliott P, Eaton N, Shaddick G, . Cancer incidence near municipal solid waste incinerators in Great

15. Britain. Part 2: Histopathological and case-note review of primary liver cancer cases. British Journal of Cancer 2000; 82: 1103-6.

16. Berry M, Bove F. Birth weight reduction associated with residence near a hazardous waste landfill. Environmental Health Perspectives 1997; 105: 856-61.

17. Goldberg MS, Goulet H, Bonvalot Y. Low birth weight among infants born to women living near a municipal solid waste land fill in Montreal, Quebec. Environmental Research 1995; 69: 37-50.

18. Gilbreath S, Kaas PH. Adverse birth outcomes associated with open dump sites in Alaska native villages. American Journal of Epidemiology 2006; 164: 518-28.

19. Dolk H, Vrijheid M, Armstrong B, . Risk of congenital anomalies near hazardous-waste landfill sites in Europe: EUROHAZCON study. Lancet 1998; 352: 423-7.

Dummer TJ, Dickinson HO, Parker L. Adverse pregnancy outcomes around incinerators and

20. crematoriums in Cumbria, North West England, 1956-93. Journal of Epidemiology \& Community Health 2003; 57: 456-61.

Kloppenborg SC, Brandt UK, Gulis G, . Risk of congenital anomalies in the vicinity of waste

21. landfills in Denmark: An epidemiological study using GIS. Central European Journal of Public Health 2005; 13: 137-43.

22. Vrijheid M, Dolk H, Amstrong B, . Hazard potential ranking of hazardous landfills sites and risk of congenital anomalies. Occupational \& Environmental Medicine 2002; 59: 768-76.

23. Jarup L, Morris S, Richardson S, . Down syndrome in births near landfill sites. Prenatal Diagnosis 2007; 27: 1191-6.

24. Abul S. Environmental and health impact of solid waste disposal at Mangwaneni Dumpsite in Manzini, Swaziland. Journal of Sustainable Development in Africa 2010; 12: 64-78.

25. Chifamba PC. Trace metal contamination of water at a solid waste disposal site at Kariba, Zimbabwe. African Journal of Aquatic Science 2007; 32: 71-8. 
Matsa M, Mutekwa T. From cradle to grave ... and then what? The role of environmental factors in

26. the distribution of pollutants around the city of Gweru's dumpsite. Journal of Sustainable

Development in Africa 2009; 11: 174-85.

27. Ikem A, Osibanjo O, Sridhar MKC, . Evaluation of ground water quality characteristics near two waste sites in Ibadan and Lagos. Water, Air and Soil Pollution 2002; 140: 307-33.

28. Mangizvo RV. Management practices at the Mucheke solid waste disposal site in Masvingo city, Zimbabwe. Journal of Sustainable Development in Africa 2009; 10: 147-64.

29. Manyanhaire IO. A preliminary appraisal of a waste dumpsite in Zimbabwe: A case of Mutare dumpsite in Manicaland province. Journal of Sustainable Development in Africa 2009; 11: 367-77.

30. Jerie S. Sound sanitary landfilling: A sustainable option for waste disposal in Harare and Gweru, Zimbabwe. OSSREA Bulletin 2005; 2005(2): 78-87.

31. Rankokwane B, Gwebu TD. Characteristics, threats and opportunities of landfill scavenging: The case of Gaborone-Botswana. GeoJournal 2006; 65: 151-63.

Makwara EC, Magudu S. Confronting the reckless gambling with people's health and lives: Urban

32. solid waste management in Zimbabwe. European Journal of Sustainable Development 2013; 2: 6798.

33. Mato RRAM, Kaseva ME. Critical review of industrial and medical waste practices in Dar es Salaam City. Resources, Conservation and Recycling 1999; 25: 271-87.

34. Jerie S, Tevera D. Solid waste management practices in the informal sector of Gweru, Zimbabwe. Journal of Waste Management 2014; 2014: Article ID 148248 (7 pp.).

35. Agunwamba JC. Solid waste management in Nigeria: Problems and issues. Environmental Management 1998; 22: 849-56.

36. Yang CY, Chang WT, Chuang HY, . Adverse health effects among household waste collectors in Taiwan. Environmental Research 2001; 85: 195-9.

Inyang M. Health and safety risks among municipal solid waste collectors in Port Harcourt

37. Metropolis of Niger Delta region of Nigeria. In: ICWMEGGSD Conference on Waste

Management, Environmental Geotechnology, and Global Sustainable Development, Ljubljana, 2830 August 2007, paper no. ID 012, pp. 1-13. Ljubljana: ICWMEGGSD.

38. Sabde YD, Zodpey SP. Respiratory morbidity among street sweepers at Hanumannagar Zone of Nagpur Municipal Corporation, Maharashtra. Indian Journal of Public Health 2008; 52: 147-9.

39. Wouters IM, Hilhorst SKM, Kleppe P, . Upper airway inflammation and respiratory symptoms in domestic waste collectors. Occupational \& Environmental Medicine 2002; 59: 106-12.

40. Rachiotis G, Papagiannis D, Thanasiasis E, . Hepatitis A virus infection and the waste handling industry. International Journal of Environmental Research and Public Health 2012; 9: 4498-503.

41. Thorn J, Beijer L, Rylander R, . Airways inflammation and glucan exposure among household waste collectors. American Journal of Industrial Medicine 1998; 33: 463-70.

Jayakrishnam T, Jeeja MC, Bhaskar R. Occupational health problems of municipal solid waste

42. management workers in India. International Journal of Environmental Health Engineering 2013; 2: 42.

Bunger J, Antlauf-Lammers M, Schulz TG, . Schappler-Scheele B, Hilgers R et al. A 5-year

43. follow-up study on respiratory disorders and lung function in workers exposed to organic dust from composting plants. International Archives of Occupational and Environmental Health 2007; 30612.

44. Athanasiou MI, Makrynos G, Dounias G. Respiratory health of municipal solid waste workers. Occupational Medicine (London) 2010; 60: 618-23.

Schibye B, Sogaard K, Martinsen D. Mechanical load on the low back and shoulders during

45. pushing and pulling of two-wheeled waste containers compared with lifting and carrying of bags and bins. Clinical Biomechanics 2001; 16: 549-59.

46. Kuijer P, Visser B, Kemper H. Job rotation as a factor in reducing physical workload at a refuse collecting department. Ergonomics 1999; 42: 1167-78. 
47. Kuijer P, Frings-Dresen M. World at work: Refuse collectors. Occupational \& Environmental Medicine 2004; 61: 282-6.

48. Buckle PW, Devereux JJ. The nature of work-related neck and upper limb musculoskeletal disorders. Applied Ergonomics 2002; 33: 207-17.

Abou-ElWafa HS, EI-Bester SF, EI-Gilany AH, . Musculoskeletal disorders among municipal solid

49. waste collectors in Mansoura, Egypt: A cross-sectional study. British Medical Journal Open 2012; 2: e001338.

50. Mehrdad R, Majlessi-Nssr M, Aminion O, . Musculoskeletal disorders among municipal solid waste workers. Acta Medica Iranica 2008; 46: 233-8.

51. Ivens U, Lassen J, Kaltoft B, . Injuries among domestic waste collectors. American Journal of Industrial Medicine 1998; 33: 182-9.

Robazzi MLCC, Moriya TM, Favero M, . Garbage collectors: Occupational accidents and

52. coefficients of frequency and severity per accident. Annals of Agricultural and Environmental Medicine 1997; 4: 91-6.

53. An H, Englehardt J, Fleming L, . Occupational health and safety amongst municipal solid waste workers in Florida. Waste Management \& Research 1999; 17: 369-77.

Gonese E, Matchaba-Hove R, Chirimumba G, . Occupational injuries among workers in the

54. cleansing section of the City Council's Health Services Department, Bulawayo, Zimbabwe, 20012002. MMWR Supplements 2006; 55: 7-10.

55. Bongale D, Kumie A, Tefera W. Assessment of occupational injuries among Addis Ababa city municipal solid waste collectors: A cross-sectional study. BMC Public Health 2014;14: 169.

Odewabi AO, Ogundahunsi OA, Ekor M. Effect of exposure to solid wastes in relation to 56. employment duration on some important markers of health and disease in waste management workers of Ogun State in southwest Nigeria. Human and Experimental Toxicology 2013; 32: $1231-44$.

57. Ekram W, Wahab EI ABD, Safaa M, . Adverse health problems among municipality workers in Alexandria. International Journal of Preventive Medicine 2013; 5: 545-56.

Ivens UI, Breum NO, Ebbehoj N, . Exposure-response relationship between gastrointestinal

58. problems among waste collectors and bioaerosol exposure. Scandinavian Journal of Work Environment \& Health 1999; 24: 238-45.

59. Engkvist IL. Working conditions at recycling centres in Sweden: Physical and psychosocial work environment. Applied Ergonomics 2010; 41: 347-54.

Cunningham RN, Simpson CD, Keifer MC. Hazards faced by informal recyclers in the squatter

60. communities of Asunción, Paraguay. International Journal of Occupational and Environmental Health 2012; 18: 181-7.

61. Hunt C. Child waste pickers in India: The occupation and its health risks. Environment and Urbanisation 1996; 8: 111-8.

62. Da Silva MC, Fassa AG, Siqueira CE, . World at work: Brazilian ragpickers. Occupational \& Environmental Medicine 2005; 62: 736-40.

63. Auler F, Nakashima AT, Cuman RK. Health conditions of recyclable waste pickers. Journal of Community Health 2014; 39: 17-22.

64. Abdou MHM. Health impacts on workers in landfill in Jeddah City, Saudi Arabia. Journal of the Egyptian Public Health Association 2007; 82: 320-9.

Kennedy SM, Copes R, Bartlett KH, . Point of sale of glass bottle recycling: Indoor airborne

65. exposures and symptoms among employees. Occupational \& Environmental Medicine 2004; 61: 628-35.

Ray MR, Mukherjee G, Roychowdury S, . Respiratory and general health impairments of rag

66. pickers in India: A study in Delhi. International Archives of Occupational and Environmental Health 2004; 77: 595-8.

${ }^{67}$ Lenis Ballesteros V, Arango López, Cuandros Urrengo YL. Health and informal work conditions 
among recyclers in the rural area of Medellin, Colombia, 2008. Revista de saúde pública 2012; 46: 866-74 (in Spanish).

Gutberlet J, Baeder AM, Pontuschka NN, . Participatory research revealing the work and

68. occupational health hazards of cooperative recyclers in Brazil. International Journal of Environmental Research and Public Health 2013; 10: 4607-27.

69. Lovie J, Guertin S. Evaluation of health and safety risks in municipal solid waste recycling plants. Journal of the Air \& Waste Management Association 2001; 51: 352-60.

70. Da Sliva MC, Fassa AG, Kriebel D. Musculoskeletal disorder in ragpickers in a southern city in Brazil. American Journal of Industrial Medicine 2006; 49: 327-36.

71. Gwisai RD, Areola O, Segosebe E. Respiratory and occupational health problems of scavengers in Lobatse, Botswana. Journal of Sustainable Development in Africa 2014; 16: 37-55.

72. Da Silva MC, Fassa AG, Kriebel D, . Minor psychiatric disorders among Brazilian ragpickers: A cross sectional study. Environmental Health 2006; 5: 17. 